\title{
Effect of different fiber materials on mechanical properties of polyurethane composites
}

\author{
Lei Wang ${ }^{1,}$, Wuxue Ding ${ }^{1, b}$ and Yu Sun ${ }^{1}$ \\ ${ }^{1}$ Nanjing University of Science and Technology,Nanjing 210000,China. \\ awl26809@126.com, ${ }^{\mathrm{b}} \mathrm{dwx}$ 84@163.com
}

Keywords: fiber type, composite material, mechanical properties.

\begin{abstract}
In this paper, we use the variable fiber reinforced reaction injection molding process to produce different kinds of fiber reinforced polyurethane composite materials. We analyze the effects of different types of fibers on the mechanical properties of the composites, while the tensile strength and bending performance testing - displacement curves. The changes of the density and mechanical properties of the composites were analyzed by the analysis of the fiber content from $10 \%$ to $20 \%$.Finally, according to the analysis, a fiber material is optimized.
\end{abstract}

\section{Introduction}

With the development of green, low energy consumption and light weight in the automotive industry, the research on the natural fiber reinforced composite is a new direction in the research and development of composite materials[1]. Natural plant fiber has the characteristics of low cost, light weight, high specific strength, high specific modulus and environmental protection. Plant fiber is of good performance, and can give full play to the enhancement effect of plant fiber, and effectively improve the mechanical properties of polyurethane foam, as the reinforcing material and PU. Plant fiber enhanced polyurethane foam composite materials with excellent properties so they have good application prospect in the fields, have made a great progress in research and application of automotive interior parts, such as used in the manufacture of door trim panel, dashboard, ceilings, and luggage rack.

In the current industrial production, the fiber reinforced reaction injection molding is used by most of the fiber glass fiber, Glass fiber strength is high, easy to disperse, but the existence of environmental protection is poor, difficult to degrade the problem. In order to expand the scope of application, this paper attempts to use plant fiber and carbon fiber as reinforcing material, with a view to replace the glass fiber. At present, the research on the properties of plant fiber reinforced composite materials has been a fruitful[2,3]. The domestic application of jute has also done a lot of research.GuojieWang[4]et al explored the process parameters and material microstructure of jute fiber enhancement effect of reaction injection molding products, mechanical properties.ChenChao[5] et al discussed jute carpet/PP membrane by lamination method preparing process for automotive interior materials, using the orthogonal and single factor optimization analysis of the jute carpet and PP film composite preparation process parameters.In this paper, we use the variable fiber reinforced reaction injection molding process to produce different kinds of fiber reinforced polyurethane composite materials.We analyze the effects of different types of fibers on the mechanical properties of the composites, while the tensile strength and bending performance testing -displacement curves. The changes of the density and mechanical properties of the composites were also analyzed by the analysis of the fiber content. Finally, according to the analysis, a fiber material is optimized.

\section{Experimental section}

Experiment scheme.The test was used to analyze the jute felt,jute tablets,carbon fiber,glass fiber mat four fiber materials. The remaining parameters were set as follows:pouring quantity $80 \mathrm{~g}$, mold temperature $45^{\circ} \mathrm{C}$,raw material temperature 40 ,release time $15 \mathrm{~min}$. The contrast test of different fiber materials is shown in table 1. 
Table 1 Comparison test of different kinds of fiber

\begin{tabular}{cccccc}
\hline \multicolumn{2}{c}{ Experiment number } & Fiber type & \multicolumn{2}{c}{ Fiber content } & Pouring quantity \\
\hline A1 & B1 & Jute felt & $10 \%$ & $20 \%$ & $80 \mathrm{~g}$ \\
A2 & B2 & Jute tablets & $10 \%$ & $20 \%$ & $80 \mathrm{~g}$ \\
A3 & B3 & Carbon fiber & $10 \%$ & $20 \%$ & $80 \mathrm{~g}$ \\
A4 & B4 & Glass fiber mat & $10 \%$ & $20 \%$ & $80 \mathrm{~g}$ \\
\hline
\end{tabular}

Experimental materials and equipment.Experimental materials: jute felt, jute tablets, carbon fiber, glass fiber mat,polyurethane raw materials.

Table 2 Types and properties of fiber materials

\begin{tabular}{ccccc}
\hline Fiber type & $\begin{array}{c}\text { Density } \\
\left(\mathrm{g} / \mathrm{cm}^{3}\right)\end{array}$ & $\begin{array}{c}\text { Elongation at break } \\
(\%)\end{array}$ & $\begin{array}{c}\text { Specific strength } \\
\left(\mathrm{MPa} \cdot \mathrm{cm}^{3} / \mathrm{g}\right)\end{array}$ & $\begin{array}{c}\text { Specific modulus } \\
\left(\mathrm{GPa} \cdot \mathrm{cm}^{3} / \mathrm{g}\right)\end{array}$ \\
\hline Jute fiber & 1.3 & $1.5 \sim 1.8$ & $302 \sim 595$ & 20.4 \\
Carbon fiber & 1.4 & $1.4 \sim 1.8$ & 2857 & $164 \sim 171$ \\
Glass fiber & 2.5 & 2.5 & $800 \sim 1400$ & 28 \\
\hline
\end{tabular}

Testequipment: Long fiber reinforced reaction injection molding equipment, Die casting aluminum mold, Electronic universal material testing machine CMT-4000, Pendulum impact testing machine JJ-5.5, Electronic balance.

Sample preparation.By forming complete sets of equipment, preparation of fiber reinforced products, better process parameters to be set in advance, and in accordance with the test program set by the artificial fibers of different kinds and contents, the mold is closed, remove the parts in the mold after curing reaction. Remove the parts must pass through the curing stage.The test article in an oven at a temperature of $80^{\circ} \mathrm{C}$ after maturing for 2 hours, and finally at a temperature of $20^{\circ} \mathrm{C}$, relative humidity of $60 \%$ air in flat 24 hours, to prepare a final product. Forming molds and products are shown in figure 1 and figure 2.

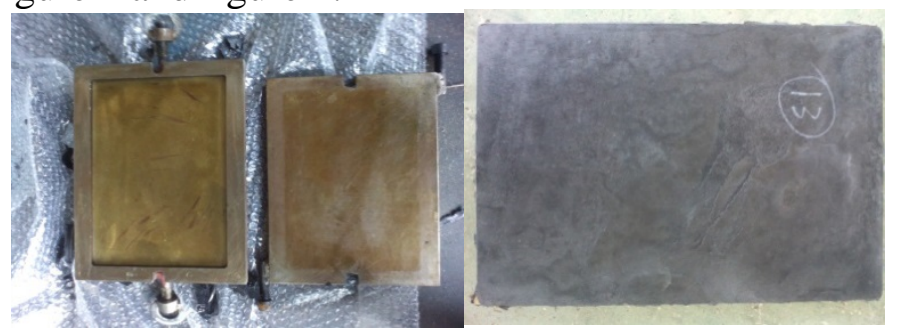

Fig. 1MoldFig. 2Product

The mechanical properties of the composite material test specimens were all on the interception of composite products, each product were tested on the interception of stretching, bending and impact test specimens each 3. In order to ensure that the mechanical properties of the samples are uniform, the edge of the product is removed, and the specific method is shown in figure 3 . Visual inspection and sample conditioning reference GB/T1446-2005 (fiber-reinforced plastics performance test method General) provisions, test temperature $(23 \pm 2){ }^{\circ} \mathrm{C}$, relative humidity of $(50 \pm 10) \%$.Finally obtained the sample shown infigure 4 .

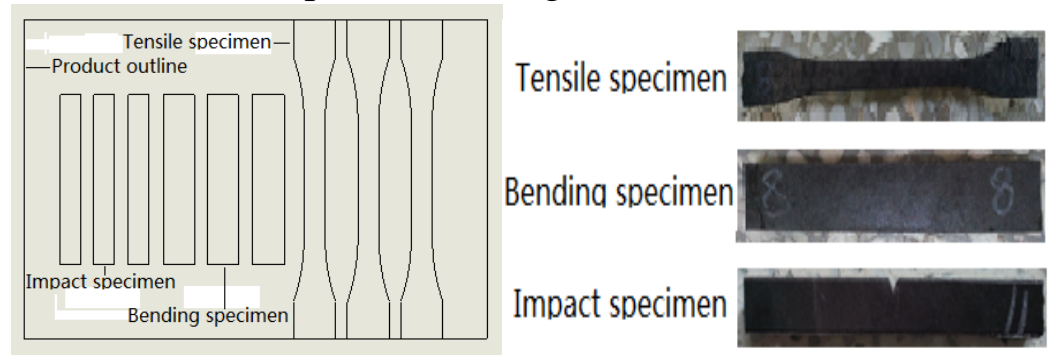

Fig. 3Intercept methodFig. 4Samples

Mechanical property test.Tensile properties of fiber reinforced composite materials was tested by GB/T1447- 2005 (tensile properties of fiber reinforced plastics). The concrete drawing process is carried out on a universal material testing machine, the clamping distance is $115 \mathrm{~mm}$, the end head width is $20 \mathrm{~mm}$, the loading rate is $10 \mathrm{~mm} / \mathrm{min}$, the test process is shown in figure 5 ; Test procedure for flexural properties of composite materials with reference to GB/T1449-2005 (fiber reinforced 
plastic bending test method). On the universal material testing machine, the three point bending test is carried out, and the pressure head and the bearing are cylindrical surface, the pressure head radius is $\mathrm{R}=5 \mathrm{~mm}$, and the supporting radius is $\mathrm{r}=2 \mathrm{~mm}$, the test speed is $10 \mathrm{~mm} / \mathrm{min}$; The impact test of fiber reinforced composite material is carried out on the JJ-5.5 pendulum impact test machine, and the test process is shown in figure 6 .

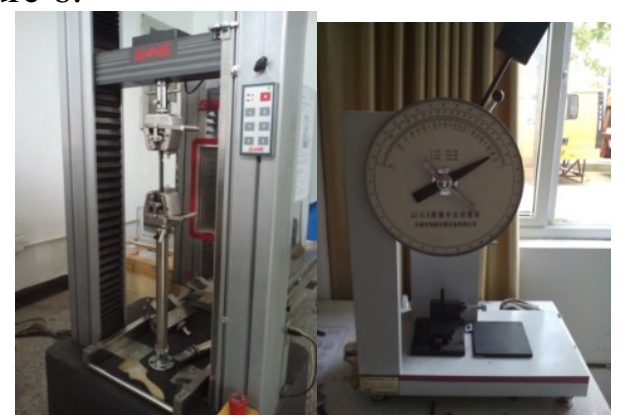

Fig. 5Electronic universal testing machineFig. 6Pendulum impact testing machine

\section{Experimental results and mechanical performance analysis}

Effects of fiber types on mechanical properties of composite materials. The test of jute felt, jute tablets, carbon fiber and glass fiber mat four fibers as a reinforcing material mechanical properties of polyurethane composites were tested,the mechanical performance test results are shown in Table 3. Fiber content was selected in $10 \%$, the pouring amount is set to $80 \mathrm{~g}$.

Table 3 Effect of different kinds of fiber on mechanical properties of composite materials

\begin{tabular}{cccccc}
\hline Fibre type & $\begin{array}{c}\text { Tensile } \\
\text { strength } \\
(\mathrm{MPa})\end{array}$ & $\begin{array}{c}\text { Tensile } \\
\text { modulus } \\
(\mathrm{MPa})\end{array}$ & $\begin{array}{c}\text { Bending } \\
\text { strength } \\
(\mathrm{MPa})\end{array}$ & $\begin{array}{c}\text { Bending } \\
\text { modulus } \\
(\mathrm{MPa})\end{array}$ & $\begin{array}{c}\text { Impact } \\
\text { strength } \\
(\mathrm{KJ} / \mathrm{m} 2)\end{array}$ \\
\hline Jute felt & 4.15 & 103.59 & 6.99 & 213.62 & 3.31 \\
Jute tablets & 3.61 & 58.30 & 5.35 & 247.00 & 2.34 \\
Carbon fiber & 14.86 & 155.72 & 13.47 & 307.90 & 8.21 \\
Glass fiber mat & 4.51 & 65.67 & 7.86 & 358.69 & 6.73
\end{tabular}

As can be seen from Table 3, jute mat reinforced polyurethane composite material mechanical properties close to glass fiber reinforced polyurethane composite material, low tensile strength than glass fiber reinforced polyurethane composite $7.9 \%$, the tensile modulus $57.7 \%$ higher bending strength , flexural modulus and impact strength were lower by $11 \%, 40.4 \%, 50.8 \%$. The mechanical properties of carbon fiber reinforced composites are higher than that of glass fiber reinforced composite, the tensile strength is 3 times higher than that of glass fiber reinforced composite. The tensile modulus and bending strength are 2 times higher, and the bending modulus is slightly lower, and the impact strength is higher than 20\%. And jutetabletsreinforced the mechanical properties of composite is lower than glass fiber reinforced composites, tensile strength, tensile modulus, bending strength, bending elastic modulus and impact strength of respectively $20 \%, 10 \%, 30 \%, 30 \%$ and $60 \%$. It showed jute felt reinforced mechanical properties of the composite is slightly lower than glass fiber reinforced composites, and jute plant fiber mat has a low cost, lightweight and environmentally friendly features, which provide a theoretical basis for the development of the jute mat reinforced composites. While jute tablets reinforced the mechanical properties of composite materials is low, the high cost of carbon fiber and the environmental pollution, are not suitable for mass production.

According to the stress transfer theory, the load is not directly related to the fiber, but first of all the material on the substrate. The force-displacement curves of tensile and flexural properties of four kinds of fiber reinforced composite materials are analyzed. The three curves in each picture are represented by the same set of three test specimens. 

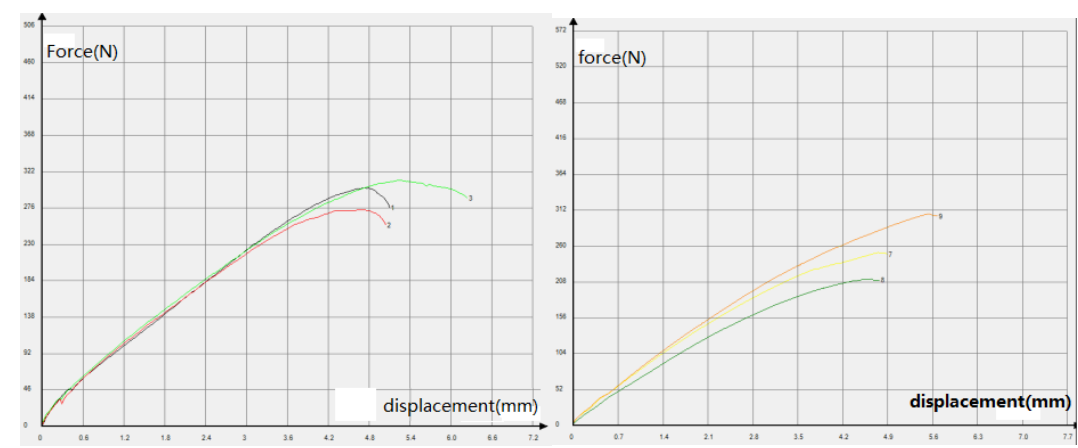

Fig. 7Jute feltFig. 8 Jute tablets
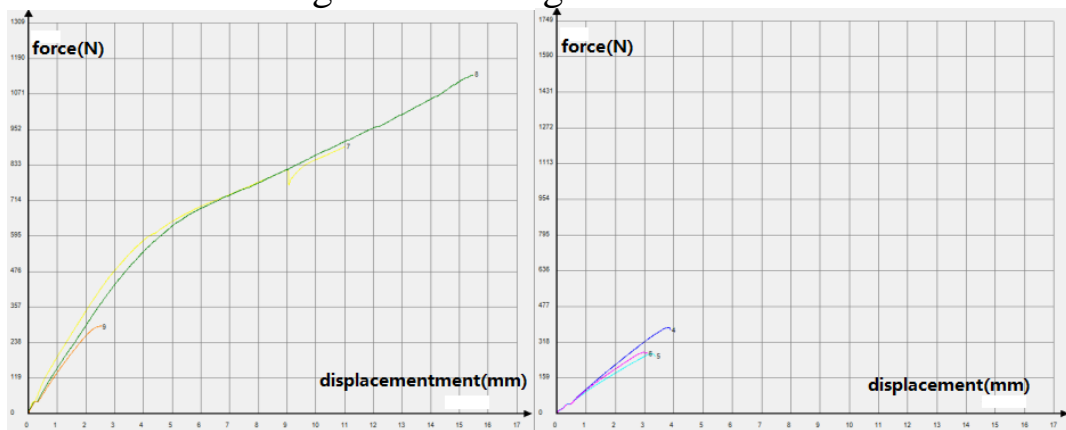

Fig. 9Carbon fiberFig. 10Glass fiber mat

Figure 7-10 are the force-displacement curves of four kinds of fiber reinforced composite tensile properties, and the force-displacement curves of the composite are all nonlinear up before the peak of the force. After the peak in force, jute felt, jute tablets and glass fiber force-displacement curve began to decline significantly. This is due to between jute felt, jute tablets, glass fiber and polyurethane matrix interfacial bonding strength is higher.Load through the substrate transfer to the fibers, in the polyurethane matrix cracking at the same time, jute felts, jute tablets and glass fiber also disrupted. However, the interface strength of carbon fiber and polyurethane matrix is not high, and the ratio of carbon fiber is high, so the interface debonding and fiber is pulled out after cracking. After the carbon fiber continues to force deformation, resulting in the carbon fiber force-displacement curve continues to rise.
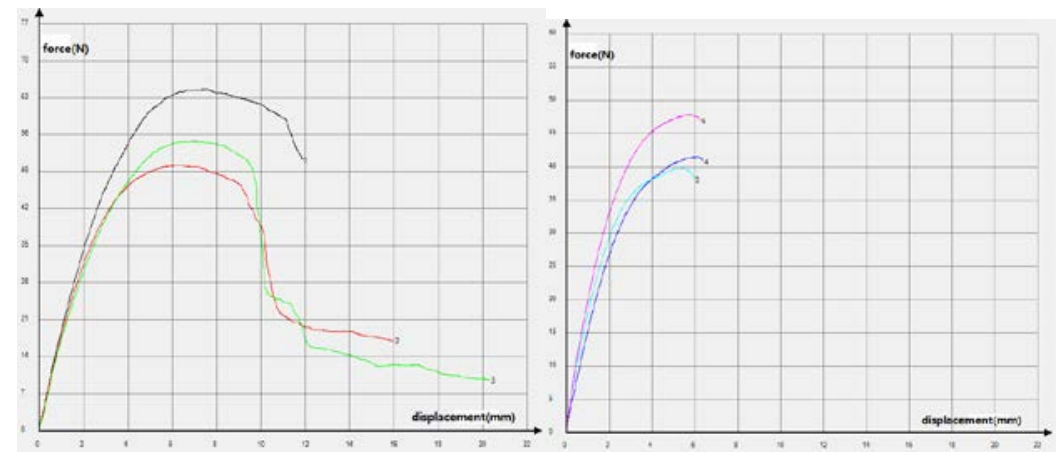

Fig. 11Jute feltFig. 12 Jute tablets
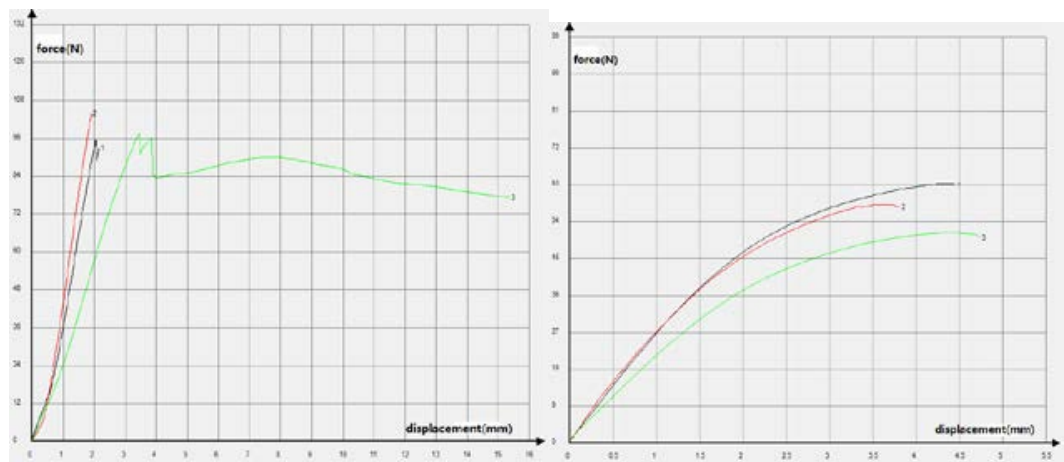

Fig. 13Carbon fiberFig. 14Glass fiber mat

Figure 11-14 are the force-displacement curves of four kinds of fiber reinforced composite 
bending performance test, the same composite force displacement curve at the peak of the force before the emergence of a nonlinear rise. After the emergence of the peak value of the force, jute felt, jute tablets and glass fiber enhanced composite force - displacement curve began to gradually slow down. Because of the high ratio of carbon fiber and the rigidity of composite material, the force-displacement curve of carbon fiber reinforced composite is rapidly decreased.

Effect of different fiber materials on the density of composite materials. With the increase of fiber content, the density of the composites increases. Taking into account the lightweight car interior decoration, density of different kinds of fiber reinforced composite materials was tested in this experiment. Test results are shown in Table 4.

Table 4 Density $\left(\mathrm{g} / \mathrm{cm}^{3}\right)$

\begin{tabular}{ccccc}
\hline Fiber content & Jute felt & Jute tablets & Carbon fiber & Glass fiber mat \\
\hline $10 \%$ & 0.35 & 0.35 & 0.39 & 0.34 \\
$20 \%$ & 0.38 & 0.39 & 0.4 & 0.42
\end{tabular}

From the table can be seen, when the fiber content is $10 \%$, the jute felt, jute tablets and glass fiber enhanced composite material of similar density, carbon fiber enhanced composite material of high density. When the fiber content increased to $20 \%$, jute felts, jute tablets and carbon fiber enhanced composite respectively increase by $8.6 \%, 11.4 \%, 2.6 \%$, and the glass fiber reinforced composite increases about $23.5 \%$. And in the fiber content of $20 \%$ glass fiber reinforced composite is higher in density, and jute felts and jute tablets enhanced composite material with low density. Therefore the development of jute felt reinforced composite material has significance for lightweight automotive interiors.

Effect of different kinds of fiber content on mechanical properties of composite materials. Usually automotive interior trim requirements better bending modulus and impact toughness, to a collision, can absorb the impact energy,reduce the auto parts on the human body harm[6]. This experiment will mainly study the influence of different kinds of fiber content on the bending modulus and impact toughness of composite materials.

Effect on bending modulus

Table 5Bending modulus (MPa)

\begin{tabular}{|c|c|c|c|c|}
\hline Fiber content & Jute felt & Jute tablets & Carbon fiber & Glass fiber mat \\
\hline $10 \%$ & 213.62 & 247.00 & 307.90 & 358.69 \\
\hline $20 \%$ & 507.98 & 311.39 & 1148.28 & 482.81 \\
\hline t on impact str & & & & \\
\hline \multicolumn{5}{|c|}{ Table 6 Impact strength $(\mathrm{KJ} / \mathrm{m} 2)$} \\
\hline Fiber content & Jute felt & Jute tablets & Carbon fiber & Glass fiber mat \\
\hline $10 \%$ & 3.31 & 2.34 & 8.21 & 6.73 \\
\hline $20 \%$ & 3.92 & 3.69 & 10.66 & 8.02 \\
\hline
\end{tabular}

From the table we can see that when the fiber content by $10 \%$ increase to $20 \%$, the bending modulus of composites are increased, jute felts, jute tablets, carbon fiber and glass fiber mat were increased by $57.9 \%, 20.6 \%, 73.1 \%$ and 25.7 . Also the impact strength of the composites are increased, jute felts, jute tablets, carbon fiber and glass fiber mat were increased by $15.6 \%, 36.5 \%$, $23 \%$ and $16.1 \%$. And when the fiber content is $20 \%$, jute felts reinforced composite bending modulus close to the glass fiber reinforced composite, but impact strength is low. Reinforcing fibers can be distributed uniformly and subjected to load, and can be effectively transmitted and resistant to stress. When the fiber mass fraction is lower, the fiber spacing is larger, the effective contact area between the plant fiber and the matrix material is less, and the reinforcing effect of the fiber on the polyurethane matrix is not enough. So it can improve the strength of the composite materials by reasonably increasing the fiber content. When the mass fraction of the fiber is too high, he matrix resin can not effectively cover the reinforcing fiber, the interfacial bonding strength of the two phases can be decreased with the increase of the fiber mass fraction, which is the main reason for the deterioration of the material properties. 


\section{Conclusion}

(1)We analyze the effects of different types of fibers on the mechanical properties of the composites, while the tensile strength and bending performance testing - displacement curves. When the fiber content is $10 \%$, jute felts reinforced composite material mechanics to glass fiber mat reinforced polyurethane composites.

(2)When the fiber content increased from $10 \%$ to $20 \%$, the density increased in the order of magnitude: glass fiber mat $>$ jute tablets $>$ jute felt $>$ carbon fiber. At the same time when the content is $10 \%$ and $20 \%$, jute felt reinforced composite material with low density.

(3)When the fiber content is increased from $10 \%$ to $20 \%$, the effect of the bending modulus is increased in the order of magnitude:carbon fiber $>$ jute felt $>$ glass fiber mat $>$ jute tablets. The effect of the bending modulus is increased in the order of magnitude: jute tablets $>$ carbon fiber $>$ glass fiber mat $>$ jute felt. When the fiber content is $20 \%$, jute carpet enhance the bending modulus of composites is higher than that of the glass fiber reinforced composite materials, and impact strength low.

(4) Based on the above analysis, jute felt reinforced polyurethane composite material has the characteristics of low cost, environmental protection, lightweight. At the same time, when the fiber content is $10 \%$ and $20 \%$, in addition to low impact strength, jute felt enhanced the mechanical properties of the composite approaches close to the glass fiber reinforced composite materials, and has a good development prospect.

\section{Acknowledgement}

This paper is based on the joint innovation fund of Jiangsu province - a prospective joint research project. Item Number is BY2014004-02.

\section{References}

[1]Sheng Xuming, Li Youbin, Progress in research on polymer based natural plant fiber reinforced composites, J.New chemical material. 40(10)1-3.

[2]MAYA J J, RAJESH D A, Recent developments inchemical modification and characterization of natural fiber-reinforced composites, J.Polymer Composites. 2008(10)187-207.

[3]JIANG Z,ASHRAF I,ROGER C, Processing a glass fiber reinforced vinyl ester composite with nanotube enhancement of interlaminar shear strength, J. Composites Science and Technology.2007(67)1509-1517.

[4]Wang Guojie,Sun Yu,Cao Chunping etc, Study on tensile properties of jute fiber reinforced polyurethane composites, J. Plastics industry, 40(8)81-84.

[5]Chen Chao, Yu Yonglin, Lv Lihua etc, Jute mat /PP film composite automotive interior materials preparationandprocessoptimization, J.JournalofDalianIndustrialUniversity.30(4)303-307.

[6]Chen Feng, Study on injection molding technology and product quality control of variable length fiber reinforced reaction injection molding, D. Nanjing University of Science and Technology. 2013:163-165. 